\title{
Las cooperativas: una alternativa de formación y autoempleo para estudiantes del ITSNCG
}

\author{
Mayte Arámbula Magallanes \\ Instituto Tecnológico Superior de Nuevo Casas Grandes \\ marambula@itsncg.edu.mx \\ Jesús Eduardo Fong García \\ Instituto Tecnológico Superior de Nuevo Casas Grandes \\ efong@itsncg.edu.mx
}

\section{Resumen}

La educación superior en su propósito de formación y contribución al desarrollo de sociedades, desarrolla trabajo colectivo que inspira al cambio en atención a las demandas sociales y de progreso local. Dichas demandas tienen que ver con grupos y comunidades vulnerables afectados por el desempleo, marginación social y desigualdad. El estudio expone el análisis del trabajo aplicado en el Instituto Tecnológico Superior de Nuevo Casas Grandes (ITSNCG) dentro de su función capacitadora y formadora de profesionistas que se enfrentan a un mercado laboral con elevada competencia y desempleo. Igualmente, se examina la influencia y alcance que tiene la educación superior a través del trabajo transdisciplinar de docentes del Instituto Tecnológico Superior de Nuevo Casas Grandes. Cuyo propósito es promover proyectos productivos como sociedad cooperativa, considerándola como alternativa de autogestión del empleo. De esta manera, se propone el impulso de las personas a cambiar su situación económica y a cubrir aspectos necesarios de capacitación técnica, superación y desarrollo de relaciones afectivas, para emprendimientos factibles. El trabajo se circunscribe en un marco de progreso regional y suscita el desarrollo de capacidades y habilidades de los estudiantes, destacando aspectos ideológicos, técnicos y procedimentales de la economía social. Apela a una visión transdisciplinaria que contribuye a la vinculación del trabajo de instituciones educativas, organismos públicos y sociedad civil.

\section{Palabras clave \\ Cooperativas, formación, autoempleo.}

\section{Introducción}

En este trabajo se muestra el estudio y análisis realizado por docentes del Instituto Tecnológico Superior de Nuevo Casas Grandes (ITSNCG), ubicado en el noroeste del estado de Chihuahua, México. Con la colaboración del Instituto de capacitación para el trabajo del Estado de Chihuahua (ICATECH). El estudio tiene un alcance social, económico y educativo en diversas carreras del ITSNCG. Como trabajo social, Kisnerman (1988), define al Trabajo Social como la disciplina que se ocupa de conocer las causas-efectos de los problemas sociales y lograr que los hombres asuman una acción organizada, tanto preventiva como transformadora que los supere. No es simplemente ejecutora de otras disciplinas sino que interviene en situaciones concretas respecto a determinadas carencias, 
investigando y coparticipando con los actores en un proceso de cambio.

Por otra parte el proceso de globalización basado en la libre movilidad de mercancías y capitales, la especialización internacional del trabajo y del conocimiento, constituyen un referente común que se despliega en todas las áreas incluida la educación superior. En la industria, la implantación de novedosos procesos de manufactura más flexibles, los círculos de calidad y la automatización son parte de los patrones de acumulación del capital en esta nueva dimensión global de la producción.

Resulta evidente que la globalización y sus trasformaciones exigen una redefinición del rol que juegan los actores sociales y políticos, entre ellos la escuela. La implantación de un nuevo orden económico aumenta las exigencias para la educación superior. El nuevo contexto requiere de instituciones educativas de nivel profesional se dediquen a formar profesionistas capacitados para un mercado de trabajo cada vez más competitivo; que les permita a las empresas insertarse exitosamente en los procesos de globalización económica.

Estas transformaciones económicas son un reto para la aportación histórica de educación pública, entendida como un bien público y un derecho irreductible. La adopción de una cultura empresarial por parte de las escuelas, trasplanta conceptos y valores ajenos a un espacio público fundamental.

El esfuerzo pedagógico se encamina a incorporar los valores del cooperativismo en la estructura curricular de la ITSNCG. Comprendiendo la trascendencia del concepto del trabajo socialmente productivo en la educación. Al asumir educación como un proceso de socialización, la escuela se convierte en un espacio público que orienta en valores solidarios y democráticos; mismos que sustentan el cooperativismo.
El desarrollo a escala humana, desarrollo de base, desarrollo de autogestión e iniciativa local es evidente ante el movimiento y papel fundamental de los actores locales del sector educativo. Lo anterior implica considerar que el ITSNCG es espacio en el que se involucra a la población o conjunto de actores sociales con cierta organización de base para gestionar proyectos que puedan favorecer al desarrollo del entorno y de la sociedad. En este caso se afirma que los actores sociales convergen en la necesidad de crear riqueza de salvaguardar los recursos naturales; la urgencia por generar empleos, y la urgencia por responder a las necesidades esenciales de la población (Nuñez, 2008).

Por tanto, el ITSNCG genera la base e intención formativa para constituir los objetivos, metas, procesos que favorecen la capacitación y formación una unidad económica basada en valores del cooperativismo, gestionada por estudiantes y profesores. Bajo la premisa de que el trabajo socialmente productivo constituye una alternativa de aprendizaje. Este último, se inspira en la visión neo marxista de Gramsci, que le atribuye al trabajo una relación instituida para equilibrar el orden natural (el trabajo) y el orden social (derechos y deberes). Para Gramsci el trabajo es inherente a la enseñanza, este se integra como momento educativo dentro de un proceso autónomo y primario.

\section{Problema y objetivos}

El fomento a la participación de grupos productivos como sociedad cooperativa para la solución de problemas de desempleo es incipiente y se siguen reproduciendo acciones y proyectos individuales cuyo impacto social es limitado e inconsistente. Así también, la ausencia de formación en valores solidarios, hacen suponer que es la razón por la que las personas que toman iniciativa por aprender algún oficio y enfrentar la realidad, no 
prospera. Debido a que el emprendimiento es individual y existe el desconocimiento de áreas de oportunidad para su desarrollo económico. Por tanto es importante estudiar la participación e influencia transdisciplinaria de actores sociales como docentes y estudiantes con potencial y capital social para la enseñanza de las cooperativas como alternativa de desarrollo regional y local. Así mismo, analizar la conformación y desarrollo humano de los actores sociales que intervienen en el estudio.

\section{Desarrollo teórico}

Las acciones emprendidas por docentes y estudiantes del ITSNCG ante la posibilidad de emprendimientos productivos representan un acercamiento a una estructura transdisciplinaria. La cual se concreta como modelo de actividades principales en la universidad transdisciplinaria mediante un esquema de coordinación, donde son esenciales las acciones recíprocas y retroalimentación entre tres tipos de unidades: educación, investigación y servicio (Apostel y otros, 1975). Aquí mismo, se argumenta que tales unidades le dan a la educación flexibilidad para cambiar de rumbo, para participar en proyectos concretos y a diferentes niveles cualitativos, para combinar la educación de estudiantes con la de adultos y para estimular las cualidades profesionales. Considerándose incluso que la estructura transdisciplinaria estará orientada hacia la humanidad y conduce a modificaciones profundas en finalidades, pensamiento y de comportamiento individual.

En relación, se tiene que el hombre crea antes que destruir, se realiza y se acepta como individuo antes de conformarse con la convención, está consciente de sí mismo, y piensa, actúa y siente en referencia a sus propias necesidades, así como en referencia a las de otros (Cofer, 2007). Se considera que el emprendimiento de empresas de economía social y lo que se circunscribe de él, trae implícito el desarrollo humano.

En este sentido, se destaca la congruencia con el concepto de la autorrealización de las personas; concibiendo persona autorrealizada como la que utiliza y desarrolla plenamente sus talentos y capacidades (Maslow citado por Craig, 2001). Algunas características de la autorrealización en la gente son: una percepción más eficiente de la realidad y relaciones más cómodas con ella, aceptación del yo y de los otros, espontaneidad, centrar problemas, separación: necesidad de intimidad, autonomía: independencia cultural y de ambiente, continua frescura en la apreciación, experiencia mística o sentimiento oceánico, interés social, relaciones interpersonales, estructura democrática del carácter, sentido del humor, creación y resistencia a la inculturación (Maslow citado por Cofer y Appley, 1990).

Es importante reconocer que las características arriba mencionadas se consideran de un modo $u$ otro, potencialidades personales. Es decir, son características fundamentales de la naturaleza humana para el impulso a la acción extraordinaria en el pleno desempeño de sus capacidades y habilidades. Sin embargo no todos los individuos logran desarrollarlas por diversos factores que dependen en gran parte del interés personal por participar y trabajar para el bien común.

Así mismo, las experiencias de gestión de proyectos cooperativistas son prácticas valiosas que pueden ser capitalizadas para fortalecer el vínculo con instituciones de educación superior y su entorno; considerando que la educación se convierte en un factor fundamental para el desarrollo en la medida que permita potenciar la organización y las redes autogestoras. Para esto Zucchetti, Gonçalvez y Mendes de Menezes (2009) refieren que la conclusión que las experiencias de producción asociada, basadas en 
autogestión y solidaridad producen saberes y la emergencia de nuevos sujetos de trabajo que hacen necesario construir otras prácticas pedagógicas, dirigidas a la formación de sujetos capaces de crear alternativas solidarias a la economía capitalista.

\section{Metodología}

El trabajo considera un proceso de estudio cualitativo en el que se explora la perspectiva de acciones realizadas en función de promover las cooperativas en medio del trabajo social y desarrollo de las capacidades y habilidades de docentes y estudiantes. De inicio se realizó un diagnóstico para identificar los rasgos importantes constituyentes de capital social de los grupos identificados en grupos de clases diversas de las carreras de Ingeniería en Gestión Empresarial, Administración, Ingeniería Industrial e Ingenieria Electrónica. Posteriormente se infiere en porqué ocurre y en qué condiciones se manifiesta el fenómeno durante platicas informativas, seguimiento y capacitación técnica respecto a la ideología de la economía social por cooperativas en los grupos.

Los datos obtenidos se complementan con la observación y entrevistas grupales. También de funcionarios públicos cuyos datos permitieron distinguir y analizar el antecedente del cúmulo de complejidades que se desarrollan en el proceso de apoyos gubernamentales otorgados para proyectos productivos. Así también, se recogen datos de la experiencia obtenida durante el proceso de capacitación que incluye la participación de docentes, residentes profesionales y estudiantes que dan cumplimiento de horas de servicio social mediante el diseño e impartición de cursos de capacitación en materia de economía social, micro negocios y computación básica.

En el origen del proyecto se evaluó el capital social y se capacitó a cinco grupos de diez identificados en las comunidades: Leona Vicario, San Buenaventura (2), Ascensión y Galeana. En el análisis se destaca la dimensión que describe la intensidad de las redes sociales y valores que surgen dentro de la interacción. Estos a su vez, generan beneficios como la coordinación de actividades, obtención de metas colectivas e individuales y que produce una mayor identidad como comunidad (Moran, 2010). Las entrevistas grupales y el cuestionario establecen una definición consensual de la comunidad donde toma lugar la investigación y permite definir las áreas de captación y el perfil organizacional que incitan a la gestión de empresas solidarias. Con entrevistas semiestructuradas a líderes comunitarios y miembros de grupos se rescatan y analizan: antecedentes, características de los grupos, rasgos culturales, costumbres e intereses. De las entrevistas a líderes identificados en cada grupo y funcionarios públicos se examinaron las formas de los programas gubernamentales y resultados poco favorables dentro de la expectativa política.

Con el análisis de la importancia del estudio se acordó entre los docentes involucrados, sumar esfuerzos para crear conciencia sobre el impacto socio-económico formativo de las cooperativas y promover su creación y crecimiento. Por tanto, dentro de la dinámica actual de la Unión de cooperativas de actividades diversas del estado de Chihuahua (UNCAD-CHIH) y fomento al cooperativismo en el año 2012, año internacional de las cooperativas (AIC)3 se promueve en el ITSNCG la creación de cooperativas y sus esfuerzos para el fortalecimiento de las comunidades, la democracia y la paz. Los grupos a los que se les ofrece la plática son de las carreras de: Administración (2), Ingeniería en Gestión Empresarial (3) e Ingeniería Industrial (1).

En algunos casos, mediante pláticas dentro de clases específicas como; 
formulación y evaluación de proyectos, creatividad gerencial, desarrollo humano y derecho; se abordan temas generales respecto a las necesidades actuales de emprendimientos, apoyos gubernamentales y particularidades de sociedades cooperativas. Igualmente, para una formación sensible y consiente de las necesidades y alternativas que se tienen de empoderamiento, autogestión de empleo y mejoramiento en la calidad de vida personal, familiar y social.

\section{Resultados y conclusiones}

La mayor amenaza para la sociedad civil es la humanidad misma, en el estado de Chihuahua y en el mundo todos los días se muestra la misma historia: desempleo, muerte, conflictos, violencia, odio, temor, pobreza, robos, hambre, violaciones, genocidio, refugiados, migración, pobreza, decadencia moral, incertidumbre económica, etc. Demostrando así que todos podemos ser nuestro gran enemigo y lo peor que puede suceder como resultado es aceptar resignadamente lo que existe y con ello perder todo impulso renovador, dando por sentada la imposibilidad de superar y trascender la situación actual.

Sin embargo, las aspiraciones de algunas personas por mejorar la calidad de vida individual y social ejercen influencia de sus capacidades y habilidades humanas de distintas maneras y en diferentes espacios. Ante esto, el concepto de calidad de vida implica y supone un estándar económico que permite satisfacer las necesidades básicas, pero requiere también crear condiciones y posibilidades reales, para el crecimiento y desarrollo humano de toda persona y de su entorno.

En este sentido, el sector de mercado de las cooperativas llamado también tercer sector, constituye una realidad de la época actual. El análisis efectuado en el origen de este estudio; desarrollado a partir de la aplicación de cuestionarios, observaciones, experiencias de capacitación ofrecida y entrevistas a grupos informales productores de la región pone de manifiesto que se trata de un sector con potencial para impulsar de forma decidida la figura del emprendedor y el autoempleo. Concretamente, en las comunidades mencionadas anteriormente se promueve la creación de 150 puestos de trabajo aproximadamente. Siendo la mayoría mujeres, amas de casa, que comparten intereses comunes y se capacitan en actividades relacionadas con: talleres de costura, elaboración de piñatas, conservas, porcicultura, avicultura y procesos derivados de la carne de cerdo. Generando a su vez, estímulos en los estudiantes para emprender organizaciones de este tipo.

Cabe señalar que los niveles de impulso y esfuerzo para emprender proyectos para su desarrollo, concurre en las variables existentes entre los grupos estudiados. Dichas variables, además de su situación geográfica; se identifican en los rasgos y actividades familiares, su situación económica, en el tiempo que tienen de conocerse, distancias vecinales, experiencias laborales negativas en compañías extranjeras, buenas o malas relaciones con funcionarios municipales $\mathrm{y}$ capacidades y habilidades de liderazgo.

De las clases y platicas se efectuó una general en el ITSNCG por los docentes involucrados, se logró convocar a más de 80 estudiantes de los cuales el interés e inquietudes por constituirse como sociedades cooperativas alcanza hasta el $36 \%$ en proyectos relacionados con crianza de la carne de cerdo, procesos industriales de valor agregado, composta, conejos y avicultura entre otros del sector primario. Estos datos, de inicio revelan la conciencia y sensibilización respecto a la problemática económica y de desempleo. Pero también la capacidad y la influencia que tiene el Instituto para la formación, estimulación y aprovechamiento de los potenciales estudiantiles para emprendimientos productivos y sus efectos. Por tanto, es 
ejemplo transdisciplinario el trabajo realizado ya que trasciende la división disciplinar mediante un esquema o modelo de coordinación. Donde los dominios o profesión de docentes que intervinieron del ITSNCG (Economía, Trabajo Social, Administración y Derecho) se vinculan con organismos públicos de capacitación para el trabajo (ICATECH) y organismos municipales para desarrollar acciones recíprocas y retroalimentación para fines económicos, sociales educativos y de investigación.

\section{Referencias}

Ander Egg, Ezequiel (1997) Metodología y práctica de la animación sociocultural. Argentina: Lumen/Hvmanitas
Castellanos Maria C., (1962). Manual de trabajo social. México: La prensa medica mexicana.

Cofer, C.N y Appley, M.H. (1990). Psicologia de la motivación. Teoría e investigación. México: Editorial Trillas.

Dabas-Najmanovich (1995). Redes el lenguaje de los vínculos. México: Paidos

Kisnerman, Natalio, (1998). Pensar el Trabajo Social una introducción desde el construccionismo (2 ed). Argentina: Ediciones Lumen Hvmanitas.

Morín, Edgar (2006). La mente bien ordenada. Barcelona. Seix Barral

Nuñez, Rodolfo Alberto (2008). Redes comunitarias. Afluencias teóricometodológicas y crónicas de intervención profesional. Argentina: Espacio Editorial. 